\title{
SISTEMA DE REJEIÇÃO DINÂMICA DE CARGAS DA USINA TERMELÉTRICA DA VALLOUREC TUBOS DO BRASIL*
}

\author{
Cristiano Pedro de Souza ${ }^{1}$ \\ Leandro Eustáquio Lima ${ }^{2}$ \\ Camilla Caroline de Moro do Carmo ${ }^{3}$
}

\section{Resumo}

A Vallourec Tubos do Brasil (VBR) possui em sua instalação uma usina Termelétrica (UTE), que utiliza os gases gerados nos altos fornos como combustível principal e gás natural como back-up. A UTE contribui para eficiência energética com a utilização dos gases excedentes dos altos fornos, além de exercer a função de "NoBreak" suprindo a energia elétrica para as cargas críticas, como altos fornos e Lingotamento Contínuo, em caso de falha da concessionária local de energia elétrica, a Cemig. A distribuição de energia para as cargas críticas opera com a UTE sincronizada com a rede da concessionária complementando a demanda de energia das cargas excedentes a geração. Para evitar o desequilíbrio entre geração e a demanda das cargas críticas, foi implantado um sistema automático de rejeição de cargas, que seleciona as cargas prioritárias e as mantêm em funcionamento, em caso de falha na distribuição da concessionária.

Palavras-chave: Termelétrica; Gás de alto forno; Rejeição de carga.

\section{Abstract}

\section{LOAD SHEDDING SYSTEM OF THERMAL POWER PLANT}

Vallourec Tubos do Brasil (VBR) has a Thermal Power Plant (UTE), which uses blast furnace gas as a main fuel and natural gas as back-up. The UTE contributes to energy efficiency of the VBR plant due to the usage of the exceeding blast furnace gas. The other function is Uninterruptible Power Supply (UPS), that it supplies electrical power to critical loads, such as blast furnaces and continuous casting in case of failure of the electricity company, Cemig. The power distribution of critical loads operates with UTE synchronized with the power system supplementing energy demand loads of the over generation. To avoid the unbalance between generation and demand of critical loads, it was implemented an automatic load shedding, which selects the priority loads and keep on working in the event of failure in the distribution of electricity.

Keywords: Thermal power plant; Blast furnace gas; Load shedding.

1 Eng $^{\circ}$ Eletricista, Coordenador de Engenharia, Gerência de Operação de Energia e Utilidades, Vallourec Tubos do Brasil S.A., Brasil.

2 Técnico em Eletrotécnica, Técnico de Processo, Gerência de Operação de Energia e Utilidades, Vallourec Tubos do Brasil S.A., Brasil.

3 Graduanda em Engenharia Elétrica, Estagiária de Engenharia Elétrica, Gerência de Operação de Energia e Utilidades, Vallourec Tubos do Brasil S.A., Brasil.

* Contribuição técnica ao $35^{\circ}$ Seminário de Balanços Energéticos Globais e Utilidades e $29^{\circ}$ Encontro de Produtores e Consumidores de Gases Industriais, 13 a 15 de agosto de 2014, São Paulo, SP, Brasil. 


\section{INTRODUÇÃO}

Após crise de energia vivenciada em 2001, visando à eficiência energética e a disponibilidade de uma fonte de energia firme para suas cargas prioritárias em caso de blecaute, a Vallourec implantou uma usina Termelétrica para gerar energia elétrica a partir do excedente de Gás de Alto Forno (GAF).

A potência da UTE foi dimensionada a partir da sobra de GAF que era queimado nas tochas para suprir as cargas prioritárias da Aciaria e Altos-Fornos.

Nos últimos anos, com a variação da disponibilidade de GAF, surgiu a necessidade de complementar a geração através do fornecimento de Gás Natural (GN) para garantir a confiabilidade da função de "No-Break" em caso de falta de energia elétrica advinda da concessionária, o que onera o custo de energia produzida pela UTE.

Buscando uma maior flexibilidade na definição da potência gerada a um custo de energia mais baixo e sem perder a confiabilidade do sistema, surgiu a necessidade de implantar a seleção variável das cargas para atender a nova demanda.

\section{SISTEMA ELÉTRICO VALLOUREC}

O sistema elétrico da Vallourec, consiste em duas entradas alimentadas por uma linha de transmissão de $138 \mathrm{kV}$, que estão ligadas na SE Barreiro da Cemig. A Entrada 1 possui um transformador trifásico de 60/75MVA e a Entrada 2 possui três transformadores monofásicos de 20/25MVA, interligados às Barras I e II de 20kV por disjuntores a vácuo, vide figura-1.

É utilizado o sistema de barra dupla e alimentada com dois disjuntores (configuração back to back), para possibilitar o paralelismo das entradas e a transferência de carga entre as barras, sem que haja a interrupção do fornecimento de energia. Atualmente para manter todo o processo produtivo da empresa, uma entrada é suficiente, tornando o sistema flexível para manutenção e operação do sistema elétrico.

As cargas críticas estão instaladas nas subestações Ferro Gusa e Aciaria, conectadas na mesma barra da UTE. Essas subestações são também responsáveis por alimentar os equipamentos de produção, distribuição de gás de alto-forno e demais utilidades para a UTE.

Em condição normal, a potência das cargas prioritárias ultrapassa a geração da UTE em aproximadamente 2,7 MW, que é complementada pelo sistema Cemig. Para manter a estabilidade do sistema elétrico na falta de fornecimento Cemig, foram identificadas as cargas menos prioritárias da Aciaria para serem desligadas pelo sistema de rejeição de carga.

* Contribuição técnica ao $35^{\circ}$ Seminário de Balanços Energéticos Globais e Utilidades e $29^{\circ}$ Encontro de Produtores e Consumidores de Gases Industriais, 13 a 15 de agosto de 2014, São Paulo, SP, Brasil. 


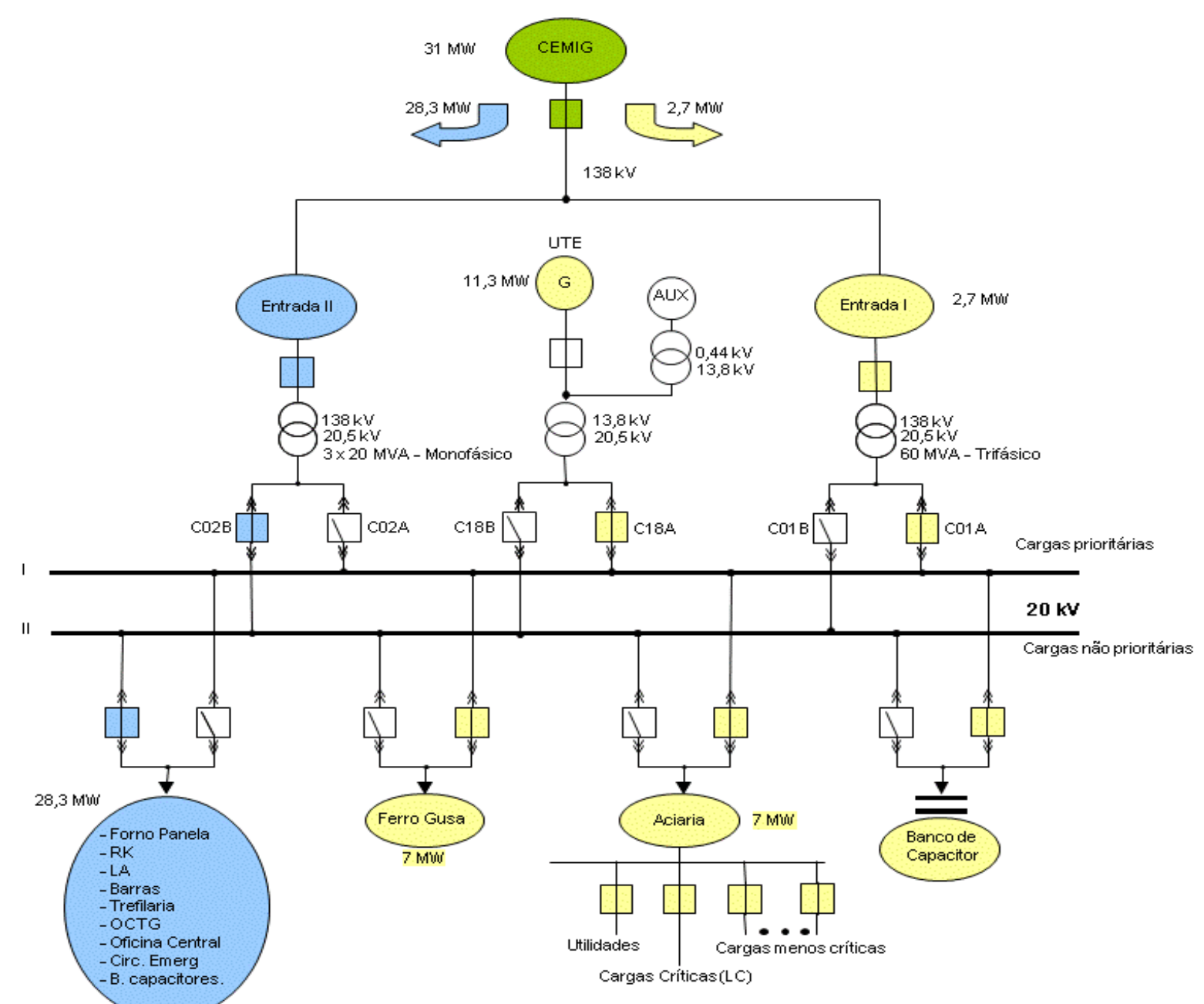

Figura 1. Sistema Elétrico da Vallourec.

\section{USINA TERMELÉTRICA - UTE}

O fluxograma da UTE e as interfaces com os processos da Vallourec estão representados na Figura 2 e principais características técnicas da UTE na Tabela 1.

Tabela 1. Características técnicas da UTE

\begin{tabular}{lc}
\hline Informações Técnicas & \\
\hline Potência nominal bruta & $12.900 \mathrm{~kW}$ \\
\hline Eficiência térmica líquida da planta - base PCl & $25,1 \%$ \\
\hline Área Construída & $4.300 \mathrm{~m}^{3}$ \\
\hline Potência consumo próprio & $1.220 \mathrm{~kW}$ \\
\hline Potência líquida & $11.3 \mathrm{~kW}$ \\
\hline Fator de disponibilidade (média anual) & $93 \%$ \\
\hline Fator de confiabilidade & $95 \%$ \\
\hline Tempo de partida da máquina a frio & $240 \mathrm{~min}$. \\
\hline
\end{tabular}

* Contribuição técnica ao $35^{\circ}$ Seminário de Balanços Energéticos Globais e Utilidades e $29^{\circ}$ Encontro de Produtores e Consumidores de Gases Industriais, 13 a 15 de agosto de 2014, São Paulo, SP, Brasil. 

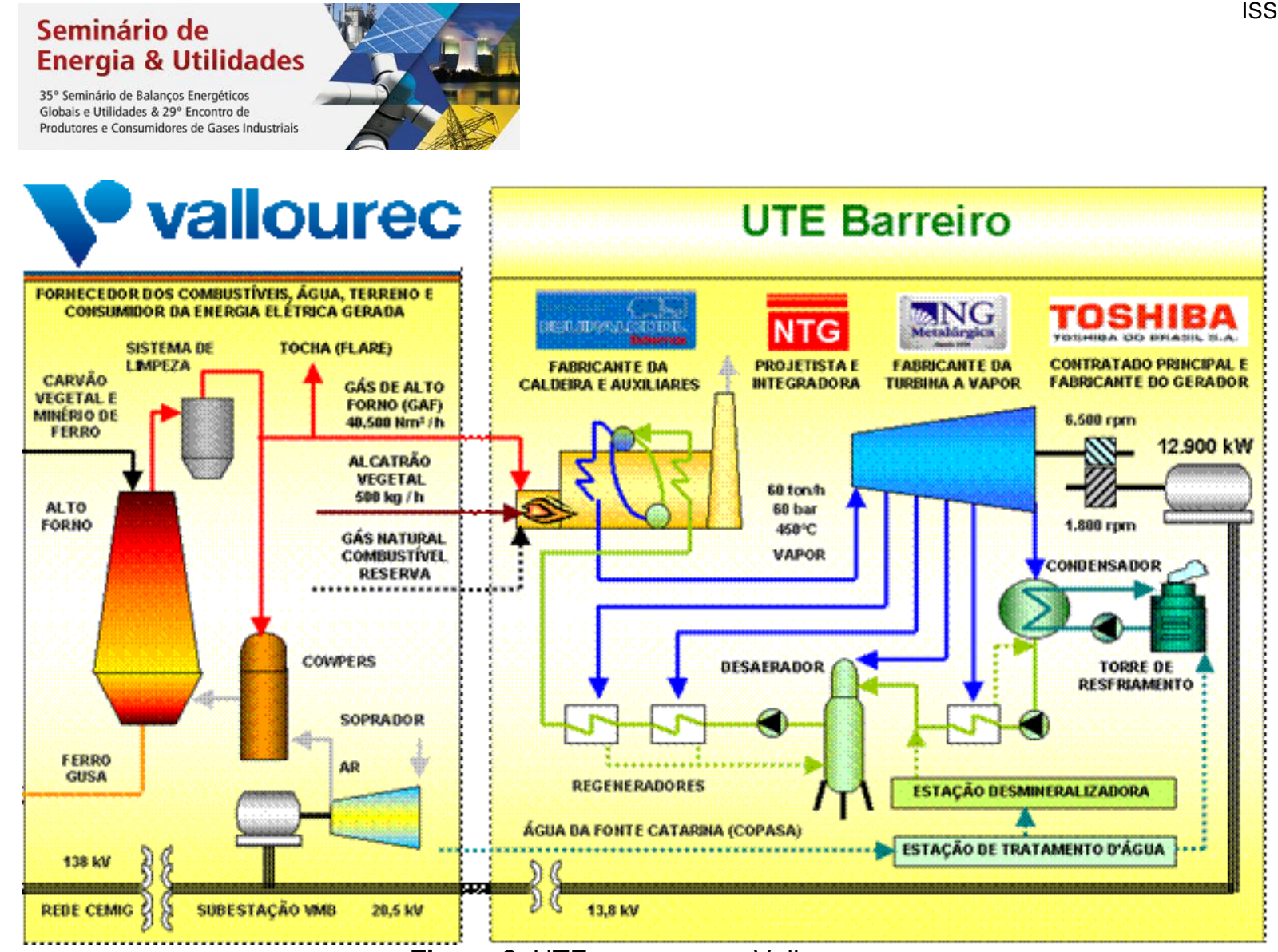

Figura 2. UTE e processos Vallourec.

\section{ILHAMENTO}

O funcionamento adequado do sistema consiste em manter a tensão e frequência estáveis dentro de uma faixa adequada ao funcionamento das cargas. Eventos tais como faltas, seccionamento de cargas ou interrupção de geração causam uma desestabilidade ao sistema [1].

Define-se como ilhamento o isolamento do barramento de $20 \mathrm{kV}$, no qual a UTE está conectada, representado na figura 3 pela abertura do disjuntor D.1. Em condições normais este barramento opera com paralelismo entre a UTE e a Cemig com o disjuntor D.1 fechado. Mediante detecção de falta na entrada de $138 \mathrm{kV}$ da subestação da VBR, imediatamente este barramento deve ser isolado do restante do sistema (barramento de cargas não prioritárias e Cemig). Esta operação denominase ilhamento da UTE.

Em situações críticas, as quais exigem o ilhamento do gerador, deve ocorrer de maneira que as variáveis tensão e frequência serão as mesmas e o ângulo de defasamento entre as tensões será mínimo. O sistema deve restabelecer o balanço de carga e geração sempre que houver variações nesta relação [2].

* Contribuição técnica ao $35^{\circ}$ Seminário de Balanços Energéticos Globais e Utilidades e $29^{\circ}$ Encontro de Produtores e Consumidores de Gases Industriais, 13 a 15 de agosto de 2014, São Paulo, SP, Brasil. 


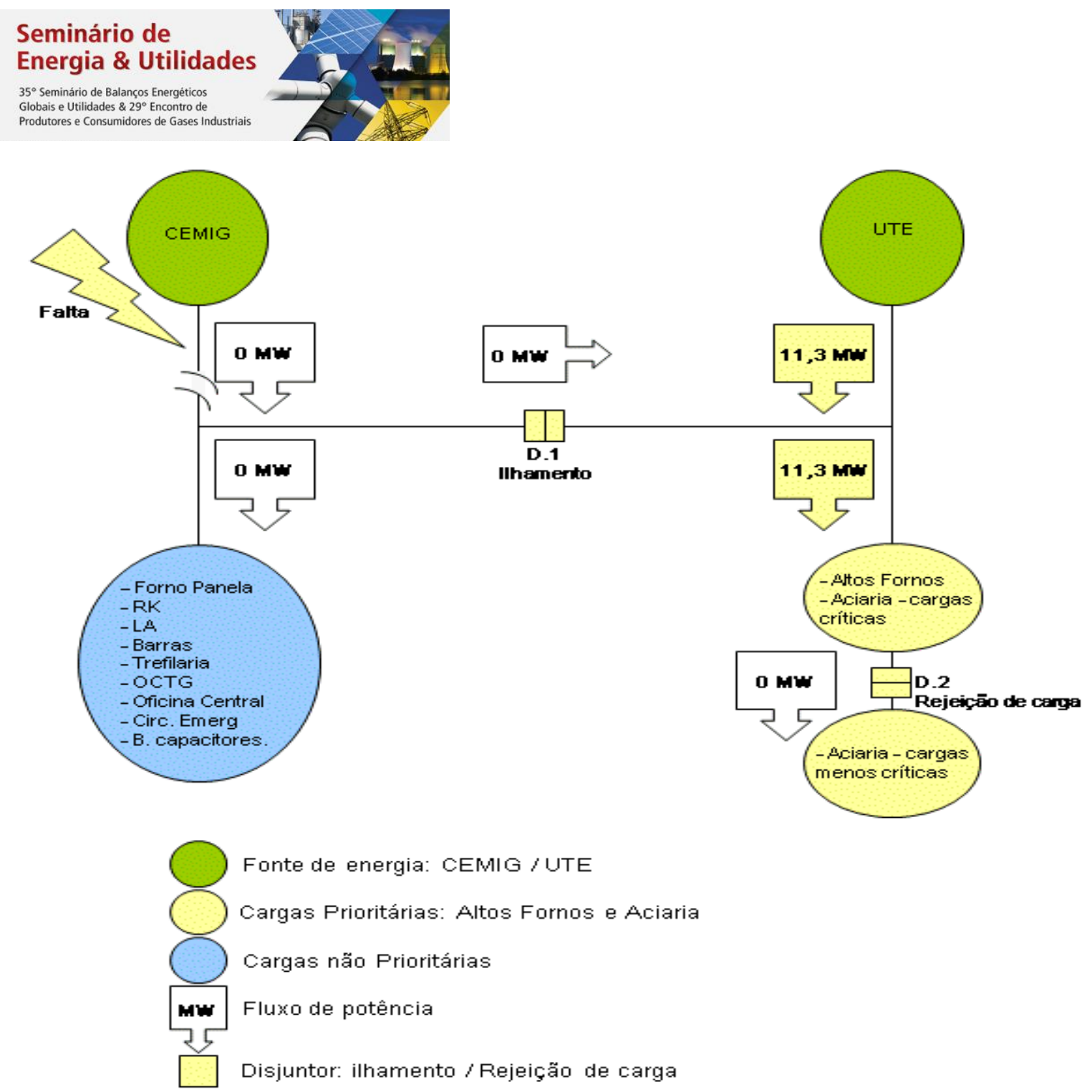

Figura 3. Representação simplificada do sistema Vallourec em condição ilhamento.

\section{REJEIÇÃO DE CARGAS}

A distribuição de cargas em um sistema elétrico com cogeração deve ser prevista a fim de prever possíveis contingências. Para isto se faz necessário a classificação das cargas prioritárias [2].

O que diferencia as cargas prioritárias daquelas não prioritárias, é a permissividade de continuidade operacional após as contingências e aquelas que garantem a segurança operacional e das pessoas. No entanto essa classificação é complexa, visto que para o funcionamento do processo, tudo é prioritário [3].

Caso a UTE tivesse potência suficiente para acionamento de todas as cargas instaladas no barramento de Cargas Prioritárias, os automatismos não seriam mais necessários, uma vez que a UTE assumiria então estas cargas. Porém, isto não ocorre. A potência nominal da UTE é inferior a das cargas instaladas. É necessário então um processo de Rejeição de Cargas. Este processo automático elimina as cargas em uma sequência de prioridade pré-definida.

No projeto atual, os processos Alto Forno e Aciaria estão conectados a este barramento. A rejeição de carga ocorre após o ilhamento com abertura automática do disjuntor D.2, e, consequentemente desligamento de cargas menos críticas da Aciaria.

* Contribuição técnica ao $35^{\circ}$ Seminário de Balanços Energéticos Globais e Utilidades e $29^{\circ}$ Encontro de Produtores e Consumidores de Gases Industriais, 13 a 15 de agosto de 2014, São Paulo, SP, Brasil. 


\section{AUTOMATISMO PARA ILHAMENTO E REJEIÇÃO}

As anomalias podem se apresentar com diversas origens e causas. Para a proteção do sistema, são utilizados relés digitais de proteção associados a um ou mais disjuntores para conter defeitos e evitar sua propagação [2].

No momento de falta de energia elétrica na entrada da subestação da VBR, a UTE tende a suprir energia para todas as cargas da Vallourec, bem como das demais cargas da Cemig vizinhas dependendo da distância da falta. Isto provoca uma rápida queda na rotação do meio primário de acionamento, que obviamente não possui potência suficiente para manter o sistema em condições normais. A queda na rotação se reflete na queda da frequência do sistema elétrico, instantaneamente e na mesma proporção. Os automatismos atualmente implantados estão baseados nesta queda de frequência. A variação da frequência no tempo (df/dt) é o parâmetro que desencadeia tanto o ilhamento quanto a rejeição de cargas.

Os relés de proteção verificam continuamente os valores de tensão e corrente. Assim que o defeito é identificado o relé envia um sinal elétrico para realizar o desligamento do disjuntor. Porém quando é utilizada a função de medição, assim como nos relés diferenciais, em mais de um ponto, que há um delay para a verificação dos dados lidos, podendo apresentar valores entre 150 e $250 \mathrm{~ms}$ [4].

O tempo de operação é fundamental para o bom funcionamento da rede elétrica, sendo necessários estudos de estabilidade para limitar o tempo para a correção das anomalias, garantindo a recuperação da tensão e da frequência do sistema [2].

\section{AUTOMATISMOS PARA ILHAMENTO E REJEIÇÃO DINÂMICA}

O sistema de rejeição de carga original operava com cargas pré-selecionadas, considerando geração nominal da UTE e perfil de consumo constante. A UTE perdia a estabilidade quando ilhada com uma demanda $30 \%$ diferente de sua geração. Isto ocorria devido a variação de consumo das cargas prioritárias no momento de ilhamento. Na figura 4, temos uma representação "estática" do sistema elétrico da VBR e UTE, com o fluxo de potência em nível de produção normal.

A utilização de relés de decaimento de frequência para sistemas de rejeição de cargas tem sido o método mais tradicional empregado em usinas termelétricas. Ultimamente, porém, sistemas mistos agregando processadores lógicos têm sido empregados com resultados satisfatórios.

Estes sistemas consistem na instalação de um processador (PLC ou relé, dependendo da extensão do sistema) que recebe em tempo real informações de demandas e estado de disjuntores de todas as cargas passíveis de rejeição, bem como das prioritárias e geração da UTE. Neste processador são então préestabelecidos cenários. A falta da energia é informada ao processador, que por sua vez, em função do último cenário estabelecido, atua ao mesmo tempo fazendo o ilhamento da UTE e selecionando as cargas que devam permanecer ou ser rejeitadas.

* Contribuição técnica ao $35^{\circ}$ Seminário de Balanços Energéticos Globais e Utilidades e $29^{\circ}$ Encontro de Produtores e Consumidores de Gases Industriais, 13 a 15 de agosto de 2014, São Paulo, SP, Brasil. 


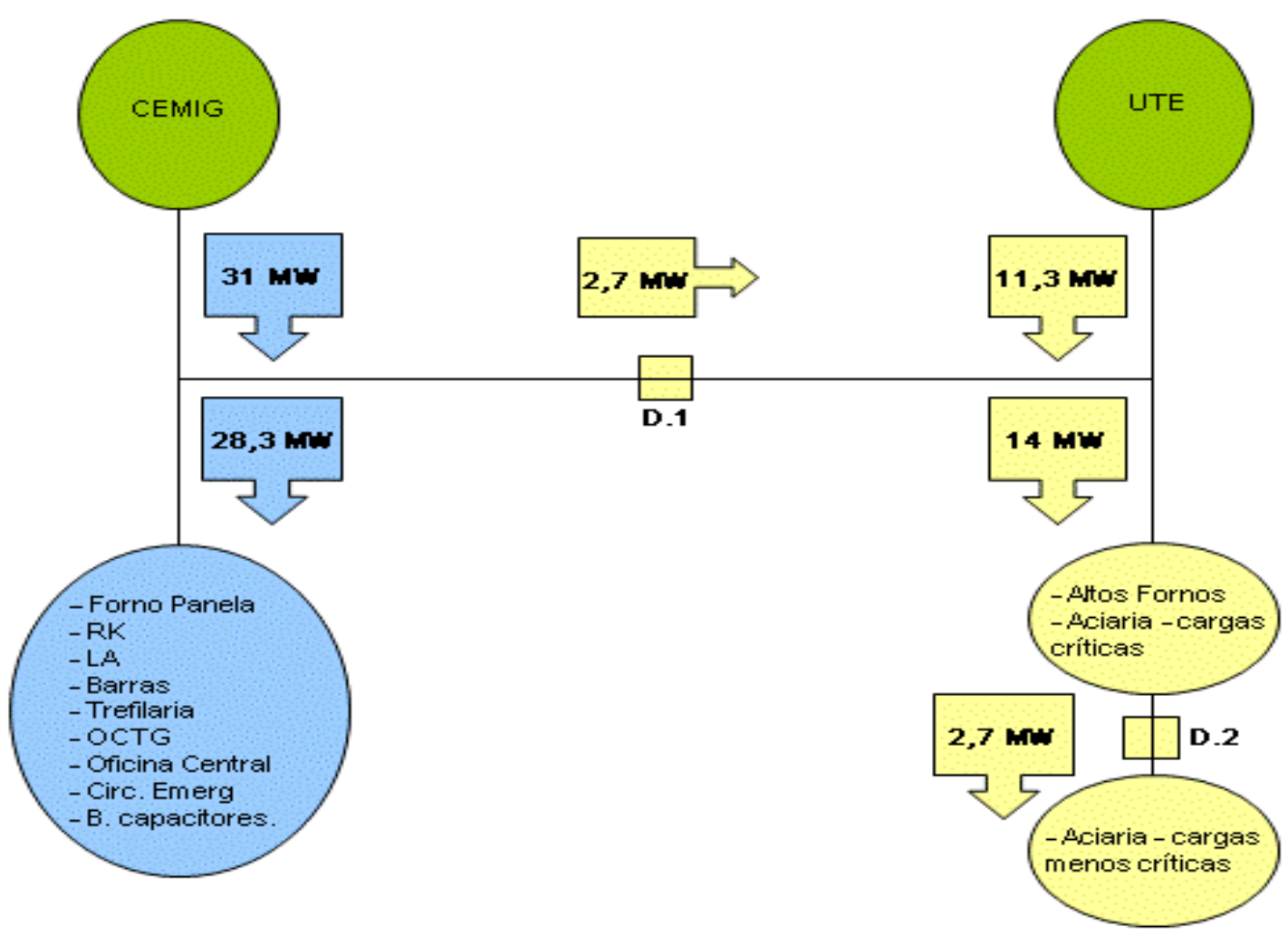

Figura 4. Representação simplificada do sistema Vallourec em condição normal.

Para tanto, o processador levará em consideração a capacidade de despacho da UTE no momento, bem como as demandas solicitadas pelas cargas do sistema. $O$ tempo de resposta do sistema será extremamente baixo, uma vez que o tempo de varredura e de processamento de equipamentos modernos está na casa de $100 \mathrm{~ms}$.

\section{RESULTADOS E DISCUSSÃO}

O sistema de controle implantado recebe em tempo real os sinais de medição das cargas prioritárias (Subestações Ferro Gusa 1 e Aciaria) e da UTE. A remota do PLC monitora o valor de geração da UTE e o consumo das cargas prioritárias. Para garantir que a diferença entre a geração e o consumo das cargas esteja dentro dos valores limites pré-determinados, a remota deve habilitar/desabilitar as cargas a serem rejeitadas. Em caso de falta do sistema da concessionária de energia elétrica Cemig, irá acontecer o ilhamento da barra prioritária e a rejeição das cargas determinadas pela remota.

O ilhamento e a rejeição acontecem de forma automática pelo acionamento do relé de subfrequência (função 81), localizado no painel da Subestação Principal onde a UTE está conectada. Para rejeição de cargas um contato NA (normalmente aberto) do relé função 81 será acionado, a remota 1 receberá um pulso e imediatamente deverá retirar todas as cargas habilitadas.

De acordo com estudos do sistema elétrico VBR, a UTE se mantém ilhada com geração próxima ao consumo de cargas prioritárias. A UTE não se mantém estável para uma diferença superior a $30 \%$ entre a geração e a demanda das cargas prioritárias, considerando as cargas eventualmente rejeitadas. Caso contrário existe o risco de falha da UTE e falta de energia geral das cargas prioritárias.

* Contribuição técnica ao $35^{\circ}$ Seminário de Balanços Energéticos Globais e Utilidades e $29^{\circ}$ Encontro de Produtores e Consumidores de Gases Industriais, 13 a 15 de agosto de 2014, São Paulo, SP, Brasil. 


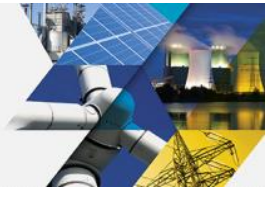

O sistema de controle implantado considera até $10 \%$ a diferença admissível entre a geração e a demanda das cargas prioritárias, considerando as cargas eventualmente rejeitadas.

Para as cargas com possibilidade de rejeição foram atribuídos valores de seleção que irão definir para o sistema a prioridade das cargas. Foram utilizados números de 1 a 29 para definir este grau de prioridade, onde o no 1 é carga mais prioritária e 0 no 29 a carga menos prioritária.

As remotas do PLC instaladas para monitoração e controle do sistema foram interligadas via fibra óptica em um sistema exclusivo para rejeição de cargas. A comunicação entre os equipamentos do sistema foi feita via rede Profinet, que oferece vantagens como: velocidade, alcance, capacidade de usar pontos de acesso, roteadores, etc.

Para maior confiabilidade do sistema, o mesmo irá efetuar comparações nas medições das cargas das Subestações que estão no barramento prioritário. Basicamente, foram criadas lógicas que comparam a medição de potência ativa da alimentação de entrada das subestações com o somatório das medições de suas respectivas cargas. O sistema irá gerar alarmes caso as diferenças percentuais estejam acima dos valores limites pré-determinados. O objetivo destas comparações é alertar ao operador caso haja qualquer desvio nas medições para que os mesmos possam atuar manualmente junto ao sistema até que seja realizada a avaliação das medições em campo.

\section{CONCLUSÃO}

O sistema de rejeição dinâmica de cargas proporciona trabalhar com a UTE em vários níveis de potência, de acordo com a disponibilidade de GAF ou um mix de combustível para obter um custo de energia otimizada, a partir do ajuste da quantidade de carga pré-selecionada em tempo real, garantindo a função de nobreak da UTE.

O sistema dispõe do monitoramento das medições de energia, redes de medidores, redes de PLC e remotas, possibilitando que o operador realize as intervenções eventualmente necessárias, tais como inserção de informação de potência de uma carga em caso de falha de medidor ou falha de comunicação e manutenção, proporcionando flexibilidade e confiabilidade mesmo em condições adversas.

\section{REFERÊNCIAS}

1 Bishop MT, Jozwowski RP. Frequency Sensing and Load Shedding Schemes. The Line Magazine. edição Agosto, p. 7-8, Cooper Power Systems. Waukesha, EUA: 1999.

2 Rennó FS. Estudo de Melhorias num Sistema de Rejeição de Cargas [Projeto de Graduação]. Vitória: Departamento de Engenharia Elétrica, Centro Tecnológico; 2007.

3 Vasconcelos A. Esquema de Proteção para Ilhamento Preventivo de Indústrias Cogeradoras. Figener S/A Engenheiros Associados. Campinas, Brasil: Sem. SEL de Confiabilidade de Sistemas Elétricos Industriais, 2006.

4 Kindermann G. Proteção de Sistemas Elétricos de Potência. 1aㅡ ed. Florianópolis: Universidade Federal de Santa Catarina; 1999.

* Contribuição técnica ao $35^{\circ}$ Seminário de Balanços Energéticos Globais e Utilidades e $29^{\circ}$ Encontro de Produtores e Consumidores de Gases Industriais, 13 a 15 de agosto de 2014, São Paulo, SP, Brasil. 